\title{
A Qualitative Exploration of Transitional Challenges Faced by Intern-nurses at Labasa Hospital, Fiji
}

\section{Devina Gaundan* and Masoud Mohammadnezhad}

School of Public Health and Primary Care, Fiji National University, Fiji

${ }^{*}$ Corresponding author: Devina Gaundan, Master in Health Services Management, School of Public Health and Primary Care, Fiji National University, Fiji, Tel: +679-9748099; Email: dgaundan@yahoo.com

Received date: April 10, 2018; Accepted date: April 23, 2018; Published date: April 30, 2018

Copyright: (c) 2018 Gaundan D, et al. This is an open-access article distributed under the terms of the Creative Commons Attribution License, which permits unrestricted use, distribution, and reproduction in any medium, provided the original author and source are credited.

Citation: Gaundan D, Mohammadnezhad M (2018) A qualitative exploration of transitional challenges faced by intern-nurses at Labasa hospital, Fiji. Health Syst Policy Res Vol. 5 No.2: 70

\section{Abstract \\ Introduction and aim: The transition of intern nurses into a full time work environment poses a lot of challenges. These challenges have an impact on the professional lives and competency of intern-nurses. This study aimed to identify the transitional challenges faced by intern-nurses at Labasa Hospital.}

Methodology: This is a qualitative phenomenological study conducted at Labasa Hospital, Fiji. The inclusion criteria for selection of participants required intern nurses to be currently employed at Labasa Hospital and be of any gender or ethnicity. The exclusion criteria comprised of nurses who did not complete internship at Labasa hospital or completed internship more than 5 years before the commencement of this study and nurses who were unwilling to participate in the interview. Data was collected through a semi-structured in depth interview of a convenient sample 22 intern-nurses. The interviews were conducted at Labasa Hospital on a one to one basis. Each interview lasted between 40 to sixty minutes. The interview data was transcribed verbatim and interpreted using thematic analysis.

Results: The participants of this study were between 22 and 26 years old. One participant was of the 46.12 of the 22 participants had completed their internship at Labasa hospital and working at various units while 10 participants were currently working as intern-nurses. Some challenges identified through thematic analysis of interview data were, bullying, exhaustion, death and dying, deployment and internship log book. The subthemes were further divided into categories. The categories reflecting bullying were being bossed round, exclusion, belittling, verbal abuse and marginalizing. Similarly, the two categories that describe exhaustion are increased workload and fatigue. The subtheme death and dying is indicated by death, palliative clients and CPR, while deployment was categorized as to other wards and to retrieve ambulance cases. Finally, time consuming, comprehensive and research proposal presentation were used to classify the subtheme internship log book.
Conclusion: Healthcare today poses a lot challenges for the intern-nurses, some of which have been identified through this study. The nursing leaders need to adapt an attitude of change in order to make changes for a smooth transition of intern nurses in order to contribute towards strengthening of nursing in Fiji.

\section{Keywords: Intern-nurses; Transition; Challenges;}

Qualitative study

\section{Introduction}

The internship period is a transitional phase for Intern-nurses to learn and equip themselves for a demanding career ahead. According to Hatler et al. the first three to twelve months of initial clinical experience is a crucial affair for the Intern-nurses [1]. Pfaff et al. states that the first year of nursing practice for intern-nurses is a challenging experience as they strive to build confidence in their professional practice [2]. Parker et al. highlighted that the most challenging period for a new nurse are the initial months of employment as they were required to manage routines, workloads, anxiety about administration of medications, and dealing with different conditions [3]. Additionally, Parker et al. found that in spite of having prior knowledge of dealing with stressful situations in clinical areas, the Intern-nurses classed their first hand experiences as disappointing, demoralizing and difficult. Duclos-Miller highlighted that an array of challenges including; meeting the physical demands of shift work, adapting to new roles/ relationships and accepting professional accountability [4]. Some of the challenges identified in past literature are bullying, burnout, workplace violence and reality shock.

Workplace bullying is a continual pattern of exploitation from others in the workplace aimed at hurting a victim. Bullying may include verbal or non-verbal abuse, intimidating behaviour, as well as, physical abuse and humiliation [5]. It is usually directed towards less experienced or new nurses in the ward in order to undermine their confidence or prove superiority [6]. The implications of bullying in the nursing profession have been reported to include sleep disturbances, health issues, lack of 
motivation to go to work, and communication break down with colleagues [7]. As indicated, prolonged bullying has a number of immediate and long term impacts, including burnout.

Burnout is defined as physical, mental and emotional exhaustion, which is characterized by disengagement leading to dulled emotions, detachment from regular friends and family, undermining motivation, and resulting in a sense of hopelessness. Some of the reasons for burnout as stated by Erikson are long shifts, putting others first, stressful environments, and dealing with sickness and death [8]. The implications of burnout do not only affect the individual nurse but also affects patient care leading to low patient satisfaction rates [8]. Additionally, workplace violence has been identifies as another implication of burnout.

Workplace violence is defined as any form of physical abuse, verbal or non-verbal abuse, harassment, intimidation, threatening or disruptive behaviour that occurs at the workplace. It can be initiated by colleagues, clients or administrators [9]. Workplace violence perpetrated by workmates is recognized as horizontal violence or relational aggression, while violence perpetrated by a senior or management is referred to as vertical violence. Morrow states that the most common form of horizontal violence experienced by Intern-nurses was in the form of psychological harassment which included verbal abuse, threats, intimidation, humiliation, excessive criticism, innuendos, exclusion, and denial of access to opportunity, disinterest and withholding of information [10]. Morrow also states that the impact of workplace violence include high absenteeism, unreported incidences, and leaving the profession. Workplace violence together with bullying and burnout lead to 'reality shock' [10].

'Reality shock' has been defined as an unsettling and/or jarring experience resulting from wide disparity between what was expected and what the real situation turns out to be [11] Sparacino stated 'reality shock has the same basic concept as culture shock; differences in language, customs and social norms [12]. Shipman stated that "reality shock" occurs when Internnurses lack the ability to connect nursing education with the realities of practice [13]. Shipman identified the inability to resolve conflicts, adapting to new shift routines and initiating decision on clinical issues as reasons for 'reality shock'. According to Hezaveh et al. "reality shock" results in high levels of stress in Intern-nurses and the condition can impact their physical, emotional, mental status and even their health [14]. Whilst previous literature reflects on the challenges faced by intern-nurses internationally, there was no evidence of challenges faced by intern-nurses in Fiji. This study aimed to identify the challenges faced by intern-nurses at Labasa Hospital, Fiji.

\section{Methodology}

A phenomenological qualitative approach was used to explore the transitional experiences of intern-nurses at Labasa Hospital. According to Donalek phenomenological research studies human experiences through the descriptions provided by the individuals involved. It is a research design that has been widely used in healthcare to study areas pertaining to investigating experiences in real-world settings. Participants in this study consisted of a convenient sample of 22 new graduate nurses who were employed as an intern at Labasa Hospital for more than six months or had completed an internship at Labasa hospital in the last five years. Their participation was voluntary.

Recruitment of participants was carried out by identifying potential participants through conversation with the Human resource manager. They were approached by the research assistant and given a verbal explanation and a participant information sheet outlining the purpose of the study and the timeframes of the interview. Upon agreeing to participate, each participant was asked to sign a written consent prior to the interview. Data was collected through semi-structured in-depth interviews by a research assistant. Each interview lasted between 40 to 60 minutes. All interviews were audio recorded while unstructured note were taken as well. All interview audio recordings were transcribed verbatim by the principal researcher. Following which a review of transcriptions was carried out to correct errors and to remove references to names, places and significant events to ensure anonymity for the participants. Once the transcriptions were clarified, data analysis was carried out.

Thematic analysis was the choice for data analysis in this study. It was carried out using four steps identified by Green et al. [15]; immersion in the data, coding, creating categories and the identification of themes and subthemes. The principle researcher read and reread each transcript line by line, identifying similar phrases and words than assigned numbers to that word or concept. The coded data that had similar characteristics were grouped together. Once grouping of similar data was completed, descriptive themes were identified to reflect the lived experiences described by the participants.

\section{Results}

In-depth interviews of 22 participants were conducted for data collection. 12 of the participants had completed their internship at Labasa Hospital and working at various units while the remaining 10 were working as intern-nurses at Labasa Hospital. Out of the 22 participants, one was 46 years old while the rest were between the ages of 22-26. The participants included 3 males and nineteen females. Thematic analyses of the interview findings indicate all the participants felt challenged in one way or the other. The challenges identified by the participants include; bullying, exhaustion, death and dying, deployment, and log books. The following section will explore these subthemes in closer detail.

\section{Bullying}

When asked about the challenges intern-nurses faced during transition most the participants indicated that intern-nurses were often bullied by their senior nursing colleagues sometimes, doctors, and Nurse Unit managers. Often bullying by colleagues happens in different forms. Some of the different forms of bullying recognized by participants were being bossed around, exclusion, belittling, verbal abuse and marginalizing. 
Being bossed around: P12 (a 24 years old female nurse) stated that she often felt being bossed around by her senior colleagues. She described her senior colleagues to be sitting around while instructing the intern-nurses to carry out the nursing duties:

"Some senior staffs are glued to the nurses' desk, telling the intern to do this and that"

Exclusion: P10 (a 24 years old female nurse) felt that she was being excluded. She described that she often felt that her presence was not acknowledged by doctors who called on senior staff to get the updates on clients:

"Even if I am standing there during the doctor's rounds, the doctor will call the senior nurse in case he/she needs clarification on something"

Belittling: P15 (a 25 years old female nurse) stated that the senior nursing staff used their powers to make the intern-nurses feel belittled. They would often use words that make the internnurses feel intimidated:

"Some seniors just throw their weight around and make the interns feel vulnerable. They say things like "You are just an intern!"

Verbal Abuse: P6 (a 24 years old female nurse) felt that her colleagues ere verbally abusive to intern nurses. They would use words that may hurt feelings or even speak in high pitched voice that would ridicule the intern-nurse in front of other people:

"Sometimes they (meaning senior nurses, doctors and unit managers) yell at interns in front of everyone" (P6, a 24 years female nurse)

Marginalizing: Participants highlighted being marginalized between qualification, seniority and gender. While some participants had completed a diploma in nursing and others had finished a bachelor's degree and felt there was higher expectation on them due to the fact they held a higher qualification. P18 (a 24 years female nurse) felt that her senior colleagues marginalized her by commenting on her qualification:

"I asked a senior staff how to calculate the drip rate for a paediatric patient; she commented I should have learnt it in my Bachelors"

Similarly, P2 (a 23 years old female nurse) felt that her colleagues marginalized on seniority by emphasizing on her lack of experience:

"Sometimes when you ask senior staff something, they respond by: "you didn't learn that in school?" or "You suppose to know that by now!"

P6 (a 24 years old female nurse) voiced that she felt disregarded when her nursing colleagues' behaviour towards male intern-nurses were different:

"I had a male intern nurse in my group. In our rotations, everyone gave so much importance to him. I felt inferior Even if he did something wrong, they seem to let it slide"

\section{Exhaustion}

Most of the participants had experienced exhaustion during their transition. Exhaustion often causes fatigue and mental stress. Some of the participants described having increased workload while the others indicated being fatigued.

Increased workload: P8 (a 24 years old female nurse) commented that she was overloaded with tasks as senior nurses during the shift often delegate tasks and gave her a lot more tasks to do in comparison with what the other nurses were tasked to do:

"In my surgical rotation, I had one senior nurse who would give me all the big wound dressings"

Fatigue: P24 (a 24 years old female nurse) described that some shift were so busy that she would use all her energy during the shift and often she would not take any breaks:

"In some shifts it's so busy that you can't take a break.

At the end of the shift I felt drained out. No more energy to work"

\section{Death and dying}

Death and dying were identified as causing grief and emotional disturbances amongst the participants while managing cases of long term illnesses, facing death and carrying out cardiopulmonary resuscitation (CPR) on clients.

Death: Three of the participants indicated that they were challenged by Death. They agreed that facing death is something that all health workers should be prepared for. P14 (a 26 years old female nurse) described that it's emotionally painful to witness death:

"It's painful to see someone die, to see their loved ones crying, you are there but can't help"

Palliative care: Palliative care is given to clients that have terminal conditions. Two of the participants felt that nursing palliative client is emotionally challenging. P1 (a 22 years male nurse) felt that dealing with the family of clients on palliative care is very difficult:

"It's hard to explain to someone that their loved one is not going to live long or is suffering from a terminal illness"

Cardiopulmonary Resuscitation (CPR): Cardiopulmonary Resuscitation (CPR) is a medical procedure involving repeated cycles of compression of the chest and artificial respiration, performed to maintain blood circulation and oxygenation in a person who has suffered cardiac arrest. Five of the participant's described that Cardiopulmonary Resuscitation (CPR) is a very challenging aspect of nursing. P3 (a 22 years old female nurse) felt the overwhelming responsibility of dealing with clients needing resuscitation:

"When I was in ICU, I felt I didn't know anything, there were three patients hooked onto ventilator, I didn't know what to do if one of them crashed, when do I start resuscitation? Whom do I get help from? These thoughts kept sweeping through my mind throughout the entire shift" 


\section{Deployment}

Deployment is a term used to describe being asked to work at a different ward apart from the designated ward. Majority of the participants voiced challenges pertaining to deployment. Nurses are either deployed to another ward to work for the shift or deployed to retrieve ambulance cases.

To other wards: P11 (a 24 years old female nurse) stated that deployment made her frustrated especially during the time she was sent to another ward for a whole shift which meant she would not be able to concentrate on her learning where she was initially rostered:

"There was this one time I was rostered in a medical ward, I came to work in a high spirit but then came to the ward and was sent to recover cases in PARU as the theatre nurses were doing cases, I spent the entire shift recovering cases"

Retrieval of Ambulance case: Most of the participants commented that they lacked skills in retrieving ambulance cases, either from home or from other health facility. P7 (a 22 years old female nurse) stated that she was not provided with any formal training about accompanying ambulance cases:

"We are not really taught about accompanying ambulance cases; I learnt a lot while actually bringing in cases"

\section{Internship log book}

Completing a competency log book is a requirement of each intern nurse in Fiji, however participants felt that the internship logbook was very strenuous and needs a lot of time and commitment to complete. Three subthemes that described completing the competency log book as a challenge were time consuming, comprehensive and research presentation.

Time consuming: Two out of the 22 participants commented on the timeliness of their competency log books. P8 (a 24 years old female nurse) and P22 (a 24 years old female nurse) agree that a lot of her time was taken filling the logbook:

"It takes up a lot of time"

\section{"A lot of time is taken to complete the log books"}

Apart from the log books being a time consuming task, the participants also commented on the log books being very comprehensive.

Comprehensive: Some of the participants stated that the log books consist of a lot of coverage of nursing procedures. P3 (a 22 years female nurse) described that she fatigued from filling the logbook rather than actually doing the procedures:

"I get more tired filling the logbook rather than actually doing the procedure"

Research proposal presentation: The intern-nurses are required to prepare and present a research proposal at the end of their internship rotation. Majority of the participants voiced that preparing a research proposal during transition is a lot of work. P 17 (a 22 years old female nurse) described the situation as being difficult:
"It's difficult to prepare a research proposal while working"

\section{Discussion}

Intern nurses face countless challenges at the beginning of their career [16]. Some of the challenges indicated by participants of this study are bullying, exhaustion, death and dying, deployment and the internship log book. Findings of this study are consistent with Silva et al. and Abdelsalam et al. which state that intern-nurses are faced with many challenges during their transition into nursing profession $[16,17]$. One of the challenges faced by intern-nurses at Labasa Hospital is bullying. Different forms of bullying indicated by the participants are being bossed around, excluded, belittled, verbally abused and marginalized. Senior nurses use their dominating nature to make the Intern-nurses do the work that they were initially tasked to do. Senior nurses make the Intern-nurses feel belittled by passing irrelevant comment making it difficult for the internnurses to interact with them. The participants also described being verbally abused by the senior nurses. Literature supports the participant's comments on the issue of experienced nurses being unfriendly and rude towards intern-nurses [18]. Additionally, the participants described being marginalized against sex, seniority and qualification. Statements made by participants reflecting marginalization indicate existence of a hierarchy between Intern-nurses and experienced nurses. The presence of a hierarchy between nurses is one of the factors encouraging bullying of intern-nurses in the wards.

Bullying at workplace threaten the intern-nurses' adjustment to an increased scope of practice. Bullying also leads to loss of productivity, absence from work, nurse attrition, interferes with teamwork, collaboration, communication and leads to exhaustion. Studies done by Boamah, Read, and Laschinger; Laschinger and Fida; Laschinger, Wong, and Grau elaborate on burnout out and emotional exhaustion felt by Intern-nurses [19-21]. On the contrary, the findings of this research indicate that Intern-nurses are facing exhaustion related to increased workload and fatigue. Shortage of nurse, young nursing work force and increased patient numbers are the reasons for increased work load for the intern-nurses. Sonmez and Yildrim state that increased workload restricts intern-nurses from spending enough time with the clients and leads to making mistakes [22]. In addition to the increased risk of making errors, it can result in repeatedly working long hours without adequate rest leading to nurses' long-term health issues such as diabetes, musculoskeletal problems and obesity. Another challenge identified by the participants is death and dying.

According to Zheng, Lee, and Bloomer death is an emotional and demanding experience for Intern-nurses who are not prepared to provide end of life care [23]. The participants of this study indicated that they faced emotional turmoil whist caring for dying clients. Another aspect of death and dying is the provision of palliative care. Despite palliative care being viewed as an important component of nursing education, it is an area of nursing that intern-nurses feel they are inadequately prepared for. In countries like Australia, several national bodies such as Palliative care Australia exist and provides guidance and support to nurses caring for palliative clients [24]. In Fiji, there is no such 
agency existing. The findings of this study are consistent with the findings of Croxon, Deravin, and Anderson which state that intern-nurses feel unequipped to deal with the responsibility dealing with family dynamics of a palliative client Even though intern-nurses are prepared to provide physical care for palliative clients, they have indicated that they feel unprepared for dealing with the emotions of the client and family. Malone, Anderson, and Croxon suggest intern-nurses need to have training on communication with palliative clients and their families in order to effectively deal with end of life issues [25].

Carrying out Cardiopulmonary Resuscitation (CPR) is another challenging aspect of death and dying faced by the Internnurses. The results of this study indicate that intern-nurses find themselves to be underprepared to attend to cardiopulmonary resuscitation (CPR). According to Ranse and Arbon participating in a cardiopulmonary resuscitation (CPR) is both emotionally and physically demanding [26]. Nurses who provide resuscitation have to be very skilful as well be psychologically prepared as they are the first people to provide any form of intervention when a client has a cardiac arrest. Another challenge identified by the participants was deployment.

Deployment in the context of this study means to be sent to work in other wards other than the rostered ward or accompany patients in an ambulance either from home or from other neighbouring health facilities. Deployment to other wards are usually done to cover shifts when staffs report sick or to meet the minimal number of nurses per shift. The participants voiced that once they are deployed to another ward, they are deprived from learning the nursing care in their initially rostered ward. They also indicated being asked to work in the wards that they have not worked in the past. The findings of this study supports Bowman which states that short term deployment of Internnurses have a negative impact on the nursing care [27]. He emphasizes that the deployment of nurse instigates frustration and anger within the person being deployed and often leads to improvised client care. The participants indicated that internnurses are often unprepared for deployment to other wards and it prevents them from learning.

Similarly, Intern-nurses are deployed to retrieve ambulance cases. Retrieval of ambulance cases means either getting a sick person from the communities situated in the outskirts of Labasa or accompanying admitted clients from another health facility (a health centre or a nursing station) based in the rural areas in Labasa. The participants stated they had no knowledge about accompanying sick clients in an ambulance. There is no existing literature on ward nurses being deployed to retrieve ambulance cases as internationally, ambulance has either a special nurse to retrieve cases or the task is carried out by the specially trained paramedics. Larson and Engstrom state that ambulance nurses need specialized trainings and regular refresher on resuscitation procedures in order to be confident in decision making while escorting clients to hospital [28]. The final challenge identified through this study was the internship log book.

The Intern-nurses in Fiji are tasked to complete a log book during their internship. This is a new found challenge as there are no existing literatures on the issue. The participants of this study emphasized that their log books often consume a lot of time that they could have utilized on providing nursing care to their clients. Another category identified by the participants is the research proposal presentation they are required to do at the end of internship. They indicated that it takes up a lot of their personal time and they find it demanding to do it while working. The findings of this research indicate that the internship log book needs revision so that it is precise and less time consuming.

This study recognized the challenges the current healthcare environment poses towards the Intern-nurses. We cannot resist the challenges posed by the new paradigm in nursing but strategic approaches that focus on building the competence and confidence of Intern-nurses will go a long way in making their transition from a world of academia to a clinical environment successful.

\section{Conclusion}

The findings of this study provide key insights into the challenges faced by Intern-nurses during transition. Internnurses are the future of nursing profession therefore; there is an immediate need to address the challenges they face during transition. The development of sustainable support networks for Intern-nurses will not only help them but it will strengthen the nursing profession and aid in creating a more supportive work environment [29]. This will lead to better patient care and improved organizational outcomes. Healthcare organizations need to understand that Intern-nurses need support to develop autonomy and critical thinking skills over time. Given the current shortage of nurses in Fiji, every effort should be made to address the challenges identified to engage the intern-nurses commitment into nursing.

In conclusion, to support new graduates, organizations must understand the autonomous practice and high functioning critical thinking skills develop over time with proper support. Leaders in our industry must adapt and make changes to ensure that we continue to have an adequate supply of qualified nurses to meet the needs of citizens of Fiji.

\section{Acknowledgement}

Ethical approval for this study was obtained from Fiji National University (FNU) College Health Research Ethics Committee (CHREC) and Fiji National Health Research Ethics Committee (FNHREC). Permission was obtained from the Medical Superintendent of Labasa Hospital prior to the commencement of the interviews.

\section{References}

1. Hatler C, Stoffers P, Kelly L, Redding K, Carr LL (2011) Work unit transformation to welcome new graduate nurses: Using nurses' wisdom. Nurs Econom 29: 88-93.

2. Pfaff K, Baxter P, Jack S, Ploeg J (2014) Exploring new graduate nurse confidence in interprofessional collaboration: A mixed method Study. Int J Nurs Stud. 
3. Parker V, Giles M, Lantry G, McMillan M (2012) New Graduate nurses' experiences in their first year of practise. Nurse Educ Today.

4. Duclos-Miller PA (2011) Successful graduate nurse transition: Meeting the challenge. Nurse Leader.

5. Namie G (2017) Workplace bullying.

6. Coyne E, Rands H, Gurung S, Kellett U (2015) I-Kiribati nursing graduates experience of transition from university to residential aged care facilities in Australia. Nurse Educ Today.

7. Ovayolu O, Ovayolu N, Karadag G (2014) Workplace bullying in nursing. Workplace Health 62: 370-374.

8. Erikson K (2015) Nursing burnout-Why it happens and what to do about it.

9. US Department of Labour (2017).

10. Morrow S (2009) New graduate transitions: Leaving the nest, joining the flight. J Nurs Manage 12: 278-287.

11. Business Dictionary (2017) USA.

12. Sparacino $L(2016)$ Faculty's role in assisting new graduate nurses' adjustment to practice. SAGE 2: 1-9.

13. Shipman D (2014) Lived experience of transtioning to a new graduate nurse following a prelicenture hospital based externship experience. New Southestern University Works 1.

14. Hezaveh MS, Rafil F, Khosravi S, Seyedfatemi N (2014) The experience of stress among new clinical nurses. Nurs Prac Today 4: 199-206.

15. Green J, Willis K, Hughes E, Small R, Welch N, et al. (2007) Generating best evidence from qualitative research: The role of data analysis. Aust N Z J Public Health 31: 545-550.

16. da Silva DG, de Souza Sda S, Trentini M, Bonetti A, Mattosinho MM (2010) The challenges coped by the novice in nursing practise. Rev Esc Enferm USP 44: 511-516.

17. Abdelsalam G, Basal AA, Ebrahem RA, Elnagar SA (2016) Perceptions of role transition among nursing interns at Tanta University. J Nurs Health Sci 5: 16-22.
18. Mariani B (2012) Our ethical responsibility in the transition to practise for new RNs. Pennsylvania Nurse 67: 4-7.

19. Boamah SA, Read EA, Laschinger $H$ (2016) Factors influencing new graduate nurse burnout development, job satisfaction and patient care quality: A time-lagged study. J Adv Nurs 73: 1182-1195.

20. Laschinger H, Fida R (2014) New nurses burnout and workplace wellbeing: The influence of authentic leadership and psychological capital. Burn Res 1: 19-28.

21. Laschinger H, Wong C, Grau A (2012) The influence of authentic leadership on workplace bullying, burnout and retention outcomes: A crossl-sectional study. Int J Nurs Stud 49: 1266-1276.

22. Sonmez B, Yildrim A (2015) Difficulties experienced by newlygraduated nurses in Turkey: A qualitative study of the first six months of employment. J Educ Prac 6: 104-110.

23. Zheng R, Lee SF, Bloomer MJ (2015) How new graduate nurses experience patient death: A systematic review and qualitative meta-synthesis. Int J Nurs Stud 53: 320-330.

24. Croxon L, Deravin L, Anderson J (2017) Dealing with end of lifeNew graduated nurse experiences. J Clin Nurs 27: 337-344.

25. Malone LD, Anderson J, Croxon L (2016) Are newly graduated nurses ready to deal with dealth and dying? A literature review. Nurs Palliat Care 1: 89-93.

26. Ranse J, Arbon P (2008) Graduate nurses' lived experience inhospital resuscitation: $A$ hermeneutic phenomenological approach. Aust Crit Care 21: 38 -47.

27. Bowman M (2013) Singular Publishing.

28. Larson R, Engstrom A (2013) Swedish ambulance nuses' experiences of nursing patients suffering cardiac arrest. Int J Nurs Pract 19: 197-205.

29. Jewell A (2013) Supporting the novice nurse to fly: A Literature review. Nurs Educ Pract 13: 323-327. 